\title{
Efficacy and safety of erythropoietin for traumatic brain injury
}

\author{
Motao Liu ${ }^{1,2,3 \dagger}$, Amy J. Wang ${ }^{4 \dagger}$, Yu Chen ${ }^{5 \dagger}$, Gexin Zhao ${ }^{6}$, Zhifeng Jiang ${ }^{7}$, Xinbang Wang ${ }^{8}$, Dongliang Shi ${ }^{9}$,
} Tiansong Zhang ${ }^{10}$, Bomin Sun ${ }^{1,2}$, Hua He ${ }^{11^{*}}$, Ziv Williams ${ }^{4,12}$ and Kejia $\mathrm{Hu}^{1,2,4,12^{*}}$ (D)

\begin{abstract}
Background: Recent studies regarding the effects of erythropoietin (EPO) for treating traumatic brain injury (TBI) have been inconsistent. This study conducts a meta-analysis of randomized controlled trials (RCTs) to assess the safety and efficacy of EPO for TBI patients at various follow-up time points.

Methods: A literature search was performed using PubMed, Web of Science, MEDLINE, Embase, Google Scholar and the Cochrane Library for RCTs studying EPO in TBI patients published through March 2019. Non-English manuscripts and non-human studies were excluded. The assessed outcomes include mortality, neurological recovery and associated adverse effects. Dichotomous variables are presented as risk ratios (RR) with a 95\% confidence interval (Cl).

Results: A total of seven RCTs involving 1197 TBI patients (611 treated with EPO, 586 treated with placebo) were included in this study. Compared to the placebo arm, treatment with EPO did not improve acute hospital mortality or short-term mortality. However, there was a significant improvement in mid-term ( 6 months) follow-up survival rates. EPO administration was not associated with neurological function improvement. Regarding adverse effects, EPO treatment did not increase the incidence of thromboembolic events or other associated adverse events.

Conclusions: This meta-analysis indicates a slight mortality benefit for TBI patients treated with EPO at mid-term followup. EPO does not improve in-hospital mortality, nor does it increase adverse events including thrombotic, cardiovascular and other associated complications. Our analysis did not demonstrate a significant beneficial effect of EPO intervention on the recovery of neurological function. Future RCTs are required to further characterize the use of EPO in TBI.
\end{abstract}

Keywords: Erythropoietin, Traumatic brain injury, Mortality, Neurological function improvement, Adverse events, Meta-analysis

\section{Background}

Traumatic brain injury (TBI) is a major cause of death and lifelong disability around the world, and predominantly affects younger and middle-aged people [1]. The United States Center for Disease Control estimates that

\footnotetext{
* Correspondence: hehua1624@smmu.edu.cn; dockejiahu@gmail.com

${ }^{\dagger}$ Motao Liu, Amy J. Wang and Yu Chen contributed equally to this work and should be considered co-first authors.

${ }^{11}$ Department of Neurosurgery, Third Affiliated Hospital, Second Military Medical University, Shanghai 200438, China

'Department of Neurosurgery, Ruijin Hospital, Shanghai Jiao Tong University

School of Medicine, No.197 Second Ruijin Street, Shanghai 200025, China

Full list of author information is available at the end of the article
}

TBI results in more than 280,000 hospitalizations and 2.2 million emergency department visits, and contributes to the deaths of over 52,000 people annually [2]. As the direct and indirect health-care costs of TBI are estimated at more than $\$ 76.5$ billion [3], TBI is a pressing medical and public health problem.

The mechanisms of TBI are typically divided into "primary" and "secondary" injury. Primary injury refers to the direct trauma to the brain, while secondary injury refers to the sequelae, which consists of a complex set of cellular and molecular processes inducing destruction of mitochondrial integrity, progressive neuronal loss

(c) The Author(s). 2020 Open Access This article is licensed under a Creative Commons Attribution 4.0 International License, which permits use, sharing, adaptation, distribution and reproduction in any medium or format, as long as you give appropriate credit to the original author(s) and the source, provide a link to the Creative Commons licence, and indicate if changes were made. The images or other third party material in this article are included in the article's Creative Commons licence, unless indicated otherwise in a credit line to the material. If material is not included in the article's Creative Commons licence and your intended use is not permitted by statutory regulation or exceeds the permitted use, you will need to obtain permission directly from the copyright holder. To view a copy of this licence, visit http://creativecommons.org/licenses/by/4.0/ The Creative Commons Public Domain Dedication waiver (http://creativecommons.org/publicdomain/zero/1.0/) applies to the data made available in this article, unless otherwise stated in a credit line to the data. 
through necrosis and apoptosis, accumulation of lactate, and cytotoxic swelling of cells [4]. These factors combine to reduce cerebral perfusion by causing brain edema and an increase in intracranial pressure. These deteriorations can occur for days, weeks and even months following the initial trauma, resulting in delayed tissue damage [5].

Over the past few decades, our understanding of the dynamic TBI pathophysiology has improved significantly [6]. More than 100 compounds are currently being investigated in preclinical studies for the treatment of secondary injury, drugs that are effective in animal models enter phase I clinical trials to test human toxicology, and then phase II and III clinical trials to evaluate efficacy. However, due to the fact that some earlier preclinical studies may have been poorly designed, or a conventional translational pathway assumes that the molecular mechanisms, pharmacokinetics demonstrated in animal models have the same outcome impact in human, almost all Phase II/ III TBI clinical trials have failed [7]. So more precisely drug screening and rational development approaches may have avoided the substantial financial and scientific penalties of an inevitably unsuccessful trial.

Erythropoietin (EPO), a hemopoietin growth factor with neurocytoprotective effects from the type 1 cytokine superfamily, the EPO production occurs in the spleen, liver, bone marrow, lung, also small quantities expressed in the brain [8]. Originally, the EPO was indicated in conditions where there is impaired production of red blood cells. The two primary FDA approved indications for the use of EPO stimulating agents are anemia secondary to chronic kidney disease and chemotherapy-induced anemia in patients with cancer, and generally limited to those with hemoglobin less than $10 \mathrm{~g} / \mathrm{dL}$ due to the risk of adverse effects [9]. The EPO has been also proved to be a promising neuroprotective therapeutic agent in a variety of neurological injuries including TBI [10]. In experimental models, EPO has been proved to stimulates hematopoiesis, and possess neuroprotective and neuroregenerative effects through reduction of apoptosis, relieve inflammation, oxidative stress, and excitotoxicity [11]. A meta-analysis about the effect of EPO in experimental TBI in animal models concluded that EPO could reduce the lesion volume and improve neurobehavioral outcomes, which might be beneficial in treating experimental animal modes of TBI [12]. However, EPO's mechanism of action was only partially understood through laboratory experiments, and the potential benefits and possible risks of EPO for TBI patients still need investigation. Pharmaceutical therapy with net clinical benefit had been lacking [13]. Clinical evidence of the EPO therapy quickly evolved but conveyed conflicting results [14].

One prior systematic review on EPO for TBI by Liu et al. [15] suggests that EPO reduces overall mortality and shortens hospitalization time without increasing the risk of DVT, but does not improve favorable neurological outcomes. While this study represents an important first step in interpreting the EPO for TBI literature, its investigation would have been strengthened by the inclusion of additional pertinent RCTs, analyses of multiple follow-up periods, and analysis of additional outcome measures.

Therefore, the objective of this current meta-analysis of RCTs is to carefully analyze a broader set of neurological outcomes and adverse events between EPO and Placebo Intervention, especially the different follow-up duration for mortality, to validate the efficacy and safety of EPO treatment for TBI patients.

\section{Methods}

We followed the guidelines proposed by the Cochrane Collaboration in the Cochrane Handbook for Systematic Reviews of Interventions (http://www. cochrane-handbook.org) and the recommended Preferred Reporting Items for Systematic Reviews and Meta-Analyses (PRISMA) statement to report this meta-analysis. The Institutional Review Board (IRB) approval was not required [16].

\section{Search strategy}

We conducted a systematic literature search (on April 10, 2019) of PubMed, EMBASE and the Cochrane Central Register of Controlled Trials for RCTs evaluating the efficacy or safety of EPO for TBI. We also searched the ClinicalTrials.gov registry, supplemented by manual searches of bibliographies of key retrieved articles and relevant reviews for additional published and unpublished data. We further checked the search engine "Google" for abstracts, conference proceedings, or unpublished studies. We used a combination of keywords and exploded medical subject headings $(\mathrm{MeSH})$ including "EPO", "erythropoietin" and "TBI", "traumatic brain injur", "brain injur", "head injur"." Another search using the same strategy was conducted on May 20, 2019, to identify additional publications.

\section{Inclusion criteria}

We included RCTs if they met the following criteria: (1) Population: patients with a diagnosis of TBI (Moderate or Severe); (2) Intervention: received intravenous or subcutaneous injection of EPO; (3) Comparison: placebo with no treatment; (4) Outcome measures: the primary outcome was mortality rate (while inpatient, and at 
short- and mid-term follow-ups defined as 10 weeks to 3 months follow-up and 6 months follow-up respectively), the second outcome was favorable neurological outcome (defined as the proportion of patients who achieved a GOS score of 4 or GOS-E score of 5). Regarding treatment safety, we examined postoperative complications including incidence of any thromboembolic events (including deep venous thrombosis, pulmonary embolism, cardiac arrest, myocardial infarction), and other associated adverse events (including pneumonia, sepsis, seizure, gastrointestinal complications and incidence of RBC transfusion).

\section{Study selection}

Two authors (ML and AJW) independently removed the duplicate records and screened all titles and abstracts to identify potentially eligible studies. The full text of these potentially eligible studies were then obtained to further confirm the eligibility of the study for the meta-analysis. Any disagreements regarding eligibility were arbitrated by consensus with the help of a third reviewer $(\mathrm{KH})$.

\section{Data extraction}

The two authors independently extracted data from included trials, using a standard abstraction form of excel sheet. From each study we extracted the following items: the first author, year of publication, country where the study was done, study design, number of participants, sex, age, number of cases, clinical settings, intervention, time from intervention to treatment, and comparison arm. When the raw data were not available in the publications, we searched the supplemental attachments or contacted the authors of the original reports. All data extraction in duplicate numbers were excluded and discrepancies between the two reviewers were discussed until agreement was reached.

\section{Quality assessment}

Two reviewers independently assessed the risk of bias in each of the included studies without being blinded to the authors, institutions, or manuscript journals. The eligible studies were evaluated using the Cochrane Collaboration's Tool and according to the predefined checklist of the Cochrane Database of Systematic

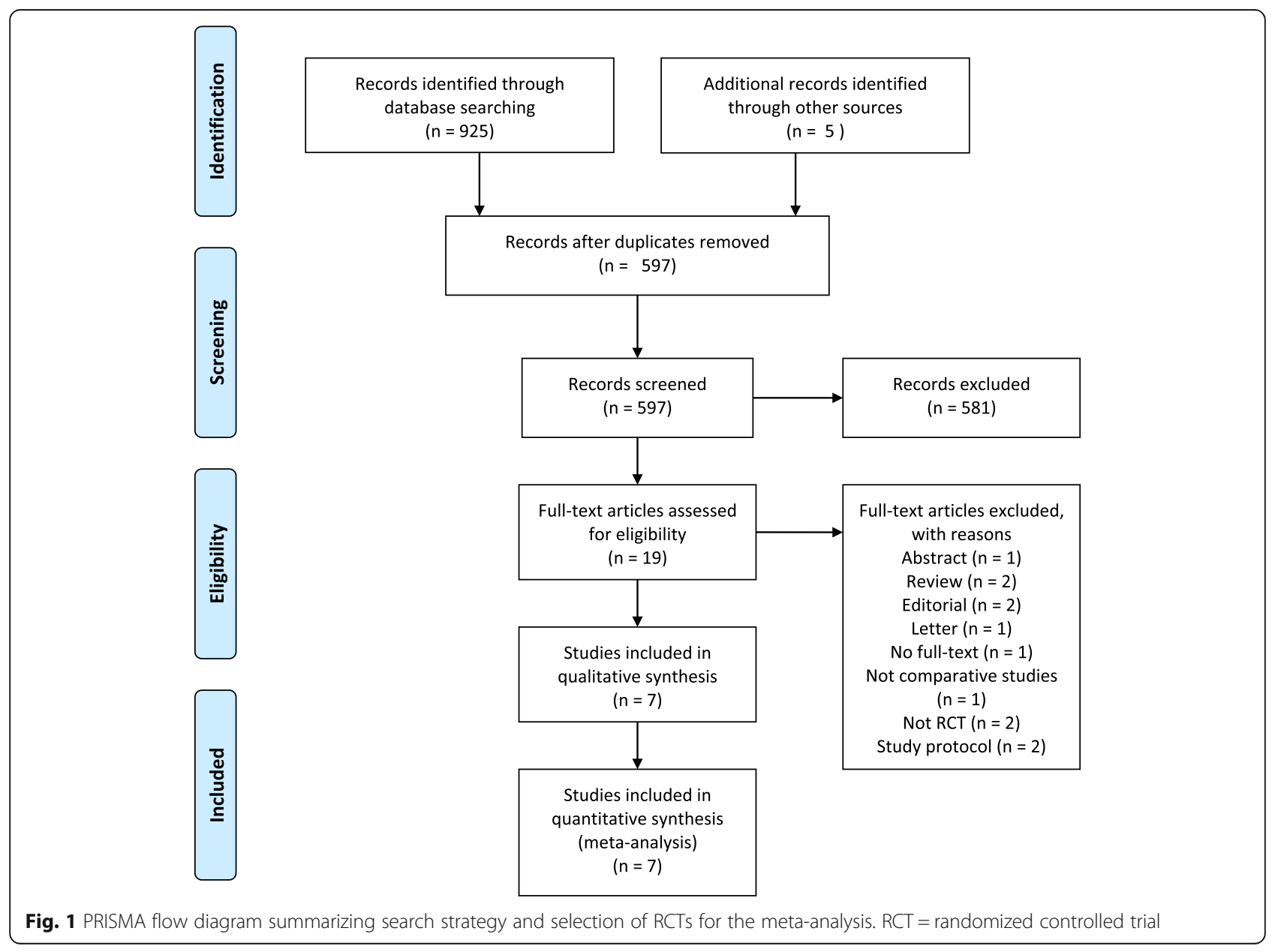




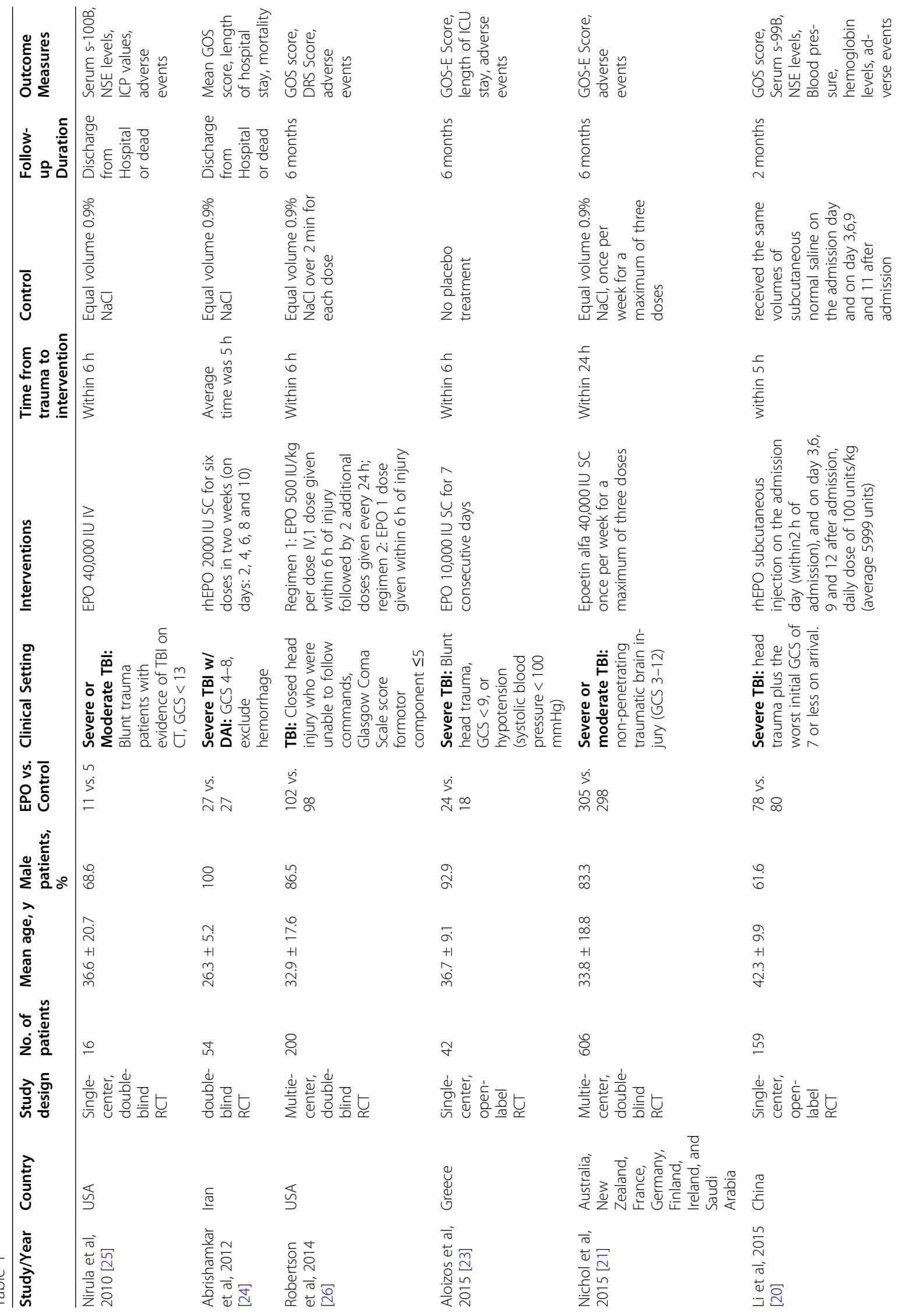




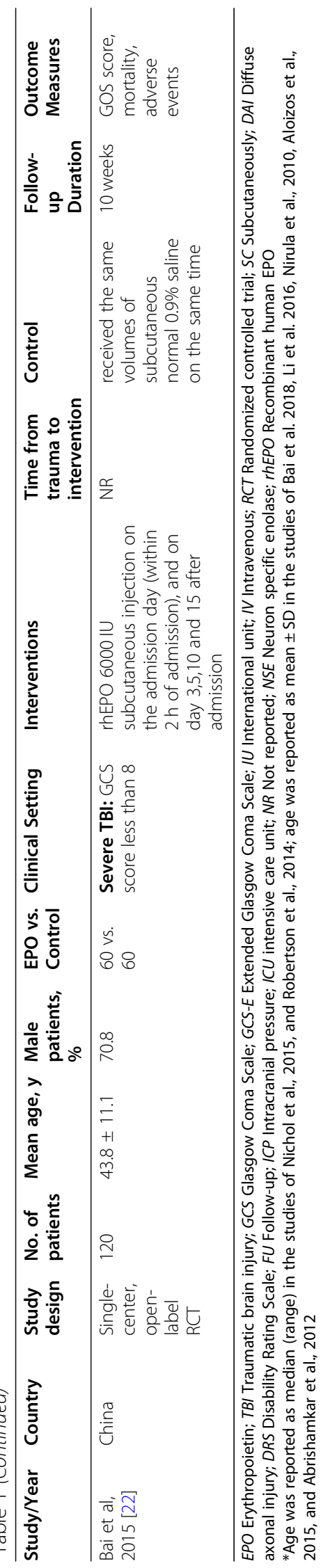


Reviews [17]. This checklist assesses the risk of bias in random sequence generation, allocation concealment, blinding of participants and personnel, blinding of outcome assessment, completeness of outcome data, degree of selective reporting, as well as other biases. Any discrepancies between the two reviewers were solved by consensus or involvement of the other reviewers.

\section{Statistical analysis}

For dichotomous and continuous outcomes, the differences between the experimental and control arms were quantified as risk ratios (RR) and mean differences (MD) with $P$ values and $95 \%$ confidence intervals (CIs). To assess the presence of heterogeneity, we used a formal Cochran Q test and quantified with the $I^{2}$ statistic [18]. We considered heterogeneity to be mild if the $I^{2}$ value was $\leq 50 \%$. We used fixed-effects meta-analyses to combine results when $I^{2} \leq 50 \%$. Otherwise, we applied a random-effects model. Potential for publication bias was assessed with the funnel plot and Egger regression test [19]. All statistical analyses were performed using Review Manager Software (RevMan version 5.3; Nordic Cochrane Centre, Cochrane Collaboration) and Stata Statistical Software (Stata 14.0, Stata Corp, College Station, Texas).

\section{Results}

\section{Study selection and characteristics}

The PRISMA statement flowchart (Fig. 1) shows the detailed process of literature screening, study selection, and reasons for exclusion. Ultimately, 1197 TBI patients (611 treated with EPO, 586 treated with placebo) from seven RCTs were included in this metaanalysis (Table 1).

Of these seven included RCTs, six studies utilized a normal saline placebo control and one study did not mention the use of placebos [20-26]. The mean age of all participants ranged from $26.3 \pm 5.2$ to $43.8 \pm 11.1$ years. The time from trauma to intervention was within

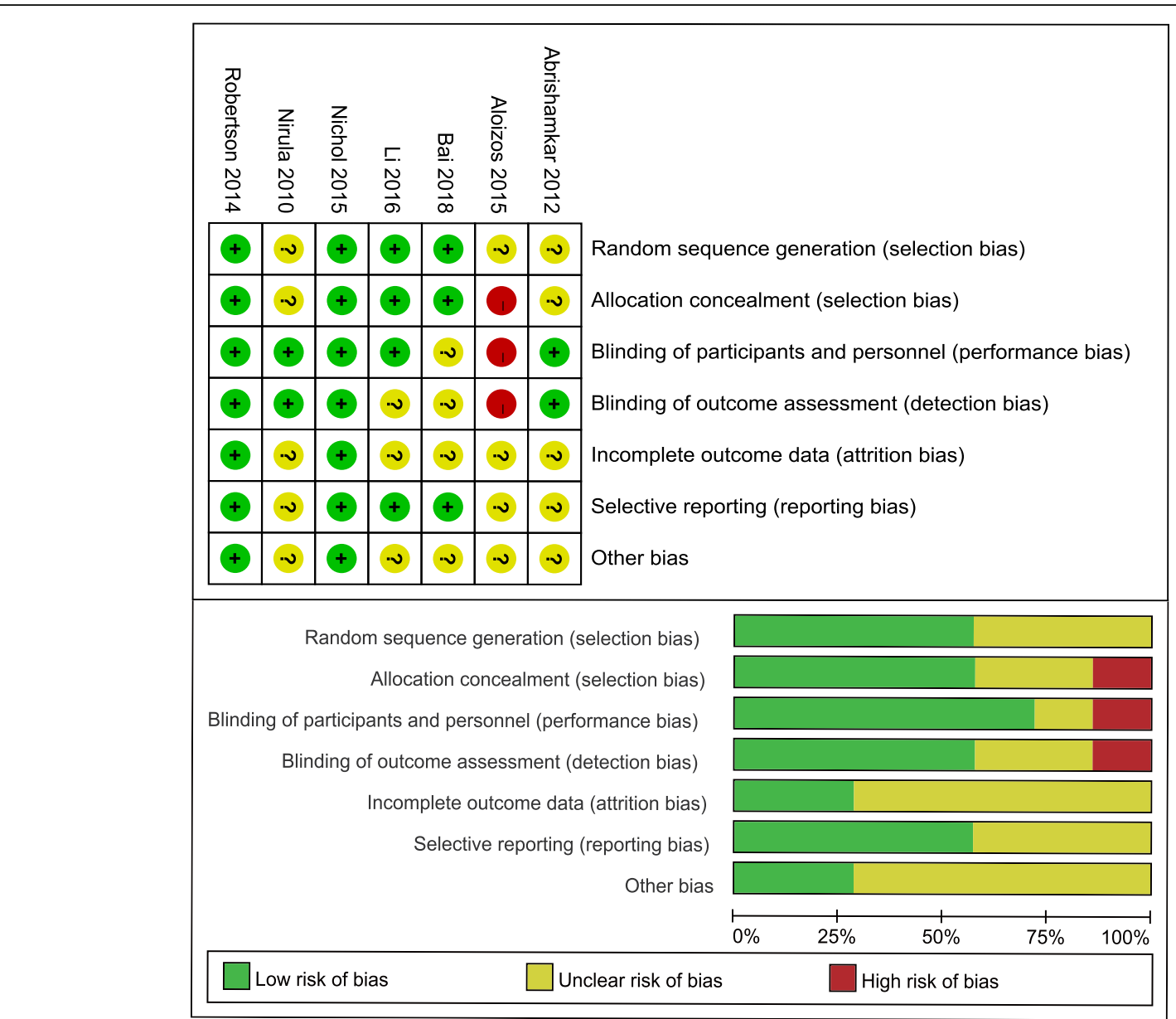

Fig. 2 Risk of bias. Upper row: Each risk of bias metric for each included study. Lower row: Review authors' judgements about each 'Risk of bias' item presented as percentages across all included studies. The overall risk of bias is relatively low. "+" indicates yes; " ${ }^{\prime \prime}$ indicates no; "?" indicates not clear 
6 to $24 \mathrm{~h}$; different EPO regimens and dosages were used: five studies injected EPO, rhEPO, or epoetin alfa subcutaneously while two gave EPO intravenously with the total dosage ranging from 12,000 international unit (IU) to $120,000 \mathrm{IU}$, and the EPO administration mostly started within $6 \mathrm{~h}$ except one started in $24 \mathrm{~h}$. In one study, Nichol et al. set a 24-h time window for recruitment, which was at odds with other included RCTs. The major characteristics of the seven RCTs are shown in Table 1 , with slightly different enrollment criteria of each [27].

\section{Quality assessment}

Our assessments of each study's risk of bias are summarized in Fig. 2. One trial was determined to be at high risk for bias [23], two trials were at low risk for bias [21, 26], and the other four were at unclear risk of bias [20, 22, 24, 25]. Four studies describe their methods for generating the randomization sequence and for allocation concealment. Five studies reported blinding of participants and investigators, which might induce performance bias.

\section{Meta-analysis outcomes \\ Mortality}

All studies reported on mortality (Fig. 3). Compared to the placebo arm, there was no significant reduction in acute hospital mortality ( $\mathrm{RR}=0.71,95 \%$ CI $[0.32-1.58]$; $P=0.41$ ) and short-term (10 weeks to 3 months followup) mortality $(\mathrm{RR}=0.64,95 \% \mathrm{CI}[0.26-1.60]$; $P=0.34$ ) in the patients with TBI. However, in our analysis of mid-term (6 months follow-up) mortality, which included a total of 792 patients $(74.5 \%$ of all included patients, drawn from the Robertson et al. 2014 and Nichol et al. 2015 studies), the EPO-treated group showed a significantly lower mortality $(\mathrm{RR}=0.69,95 \% \mathrm{CI}[0.48-0.98]$; $p=0.04)$.

\section{Efficacy of EPO on neurological recovery}

The neurological outcomes of TBI patients were evaluated by GOS or GOS-E varying from 10 weeks to 6 months (Fig. 4). only Li et al. had showed EPO significant better control group. However, EPO was not associated with favorable neurological function improvement GOS-E 5-8 ( $\mathrm{RR}=1.22,95 \% \mathrm{CI}[0.82-1.81]$; $P=0.33)$.

\section{Safety outcomes}

\section{Thrombotic and cardiovascular events}

Five studies [20-22, 25, 26] reported the incidence of thromboembolic events at the end of follow-up $(N=$ 1980). Compared to the placebo treatment, EPO therapy did not increase the incidence of total thromboembolic events ( $\mathrm{RR}=1.01,95 \% \mathrm{CI}$ [0.65-1.57]; $P=$ 0.97) in TBI patients (Fig. 5). Our analysis of pooled results demonstrate that there was no difference in rates of deep venous thrombosis $(\mathrm{RR}=0.98,95 \% \mathrm{CI}$ $[0.45-2.14] ; P=0.96)[21,22,25,26]$, pulmonary embolism $(\mathrm{RR}=1.23,95 \% \mathrm{CI}[0.63-2.40] ; P=0.54)[21$, $22,26]$, cardiac arrest $(\mathrm{RR}=1.39,95 \%$ CI $[0.53-3.61]$; $P=0.50)[21,26]$, or myocardial infarction $(R R=1.22$, 95\% CI [0.29-5.07]; $P=0.79$ ) [21, 22, 26]. (Fig. 5).

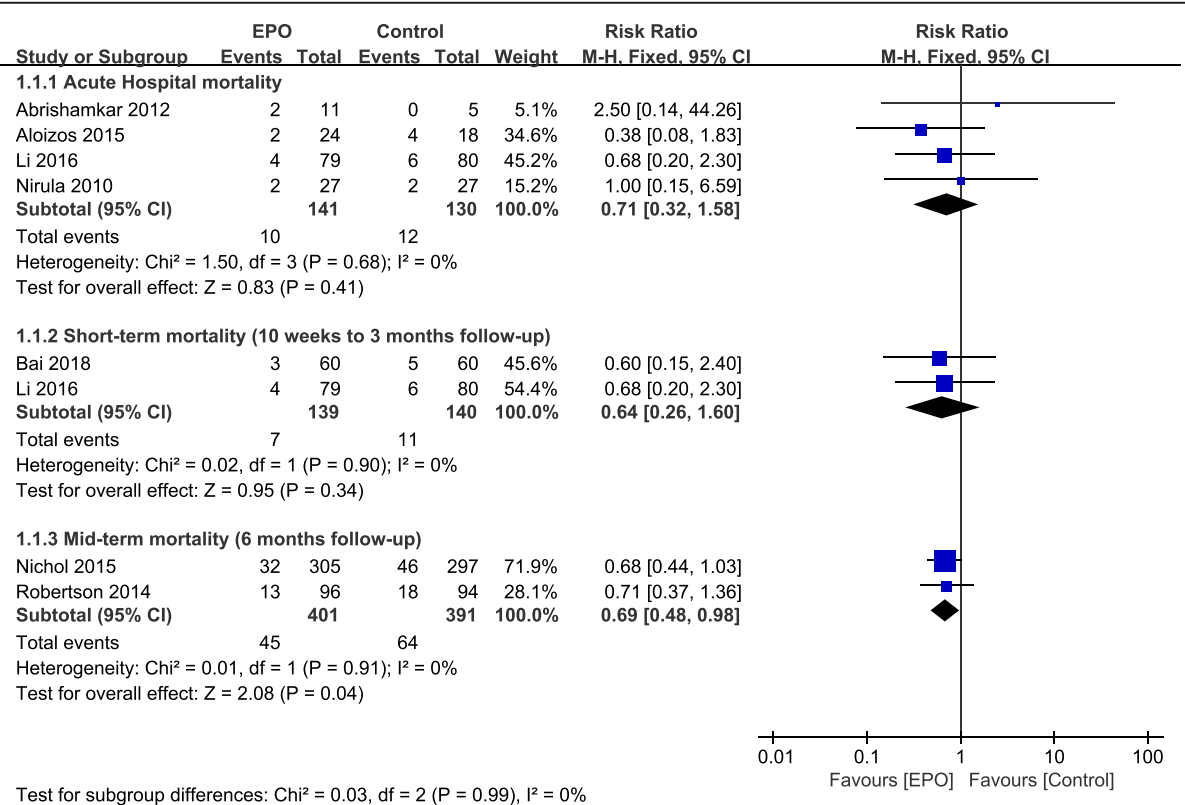

Fig. 3 Effect of EPO intervention on mortality compared with control treatment at varying lengths of follow-up. Results are shown using a fixedeffect model with Risk ratio and 95\% Cls. Cl, confidence interval; M-H, Mantel-Haenszel 


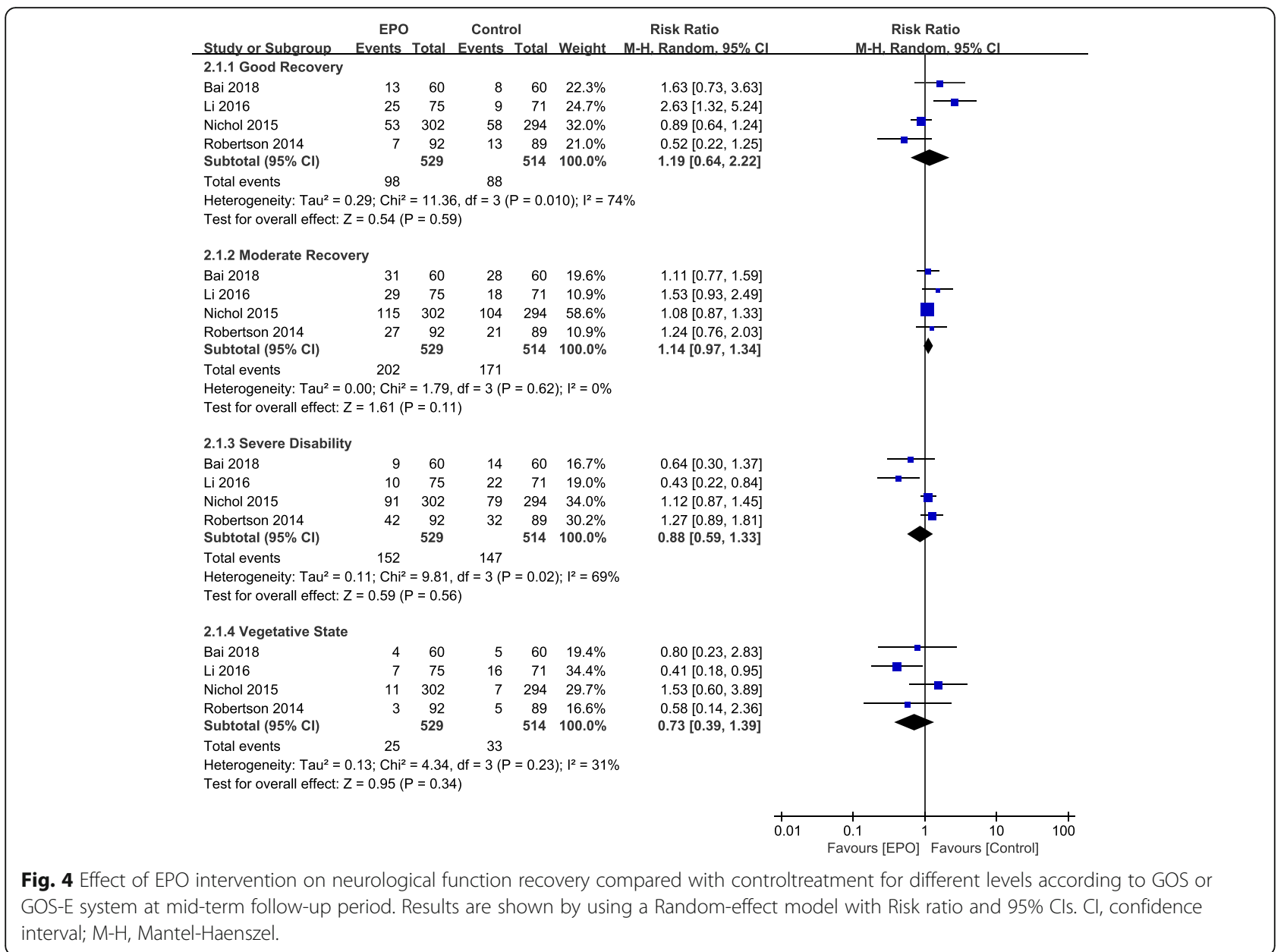

\section{Other associated adverse events}

Our pooled results showed no differences regarding other adverse events between the EPO and control groups (detail shown in Fig. 6). There were no difference in rates of pneumonia $(\mathrm{RR}=1.25,95 \% \mathrm{CI}[0.73-2.15] ; P=0.42)[20,22$, 26], sepsis (RR $=1.30,95 \%$ CI $[0.72-2.32] ; P=0.38$ ) [20$22,26], \mathrm{RBC}$ transfusion $(\mathrm{RR}=0.94,95 \% \mathrm{CI}[0.81-1.10]$; $P=0.46)[21,26]$, seizure ( $\mathrm{RR}=1.20,95 \%$ CI $[0.64-2.25]$; $P=0.44)[21,22,26]$, gastrointestinal complications $(\mathrm{RR}=$ 1.10, 95\%CI [0.74-1.64]; $P=0.63$ ) [21, 22, 26] (Fig. 6).

\section{Publication bias}

A funnel plot did not reveal any obvious asymmetry (Fig. 7), and clear evidence of publication bias was not detected by Egger's test.

\section{Discussion}

\section{Principal findings}

This meta-analysis demonstrates a survival benefit at 6 months follow-up to the administration of EPO to TBI patients. However, EPO intervention did not impact acute hospital mortality (in 10 weeks) or short-term mortality (10 weeks to 3 months). EPO therapy does not increase adverse events including thrombotic and cardiovascular complications. At the same time, EPO intervention had no significantly effect on the recovery of neurological function.

\section{Mortality}

This current study of EPO treatment in TBI patients provided a novel analysis of survival rates for different follow-up duration. The three follow-up durations included different RCTs and different numbers of participants, also no single RCT was used in all three mortality assessments. The study was well-powered enough to detect a slight but significant six-month survival benefit with EPO treatment. While the concrete mechanism of mortality reduction in patients with TBI remains unclear, studies suggest that shortterm mortality is related to either brain death or 


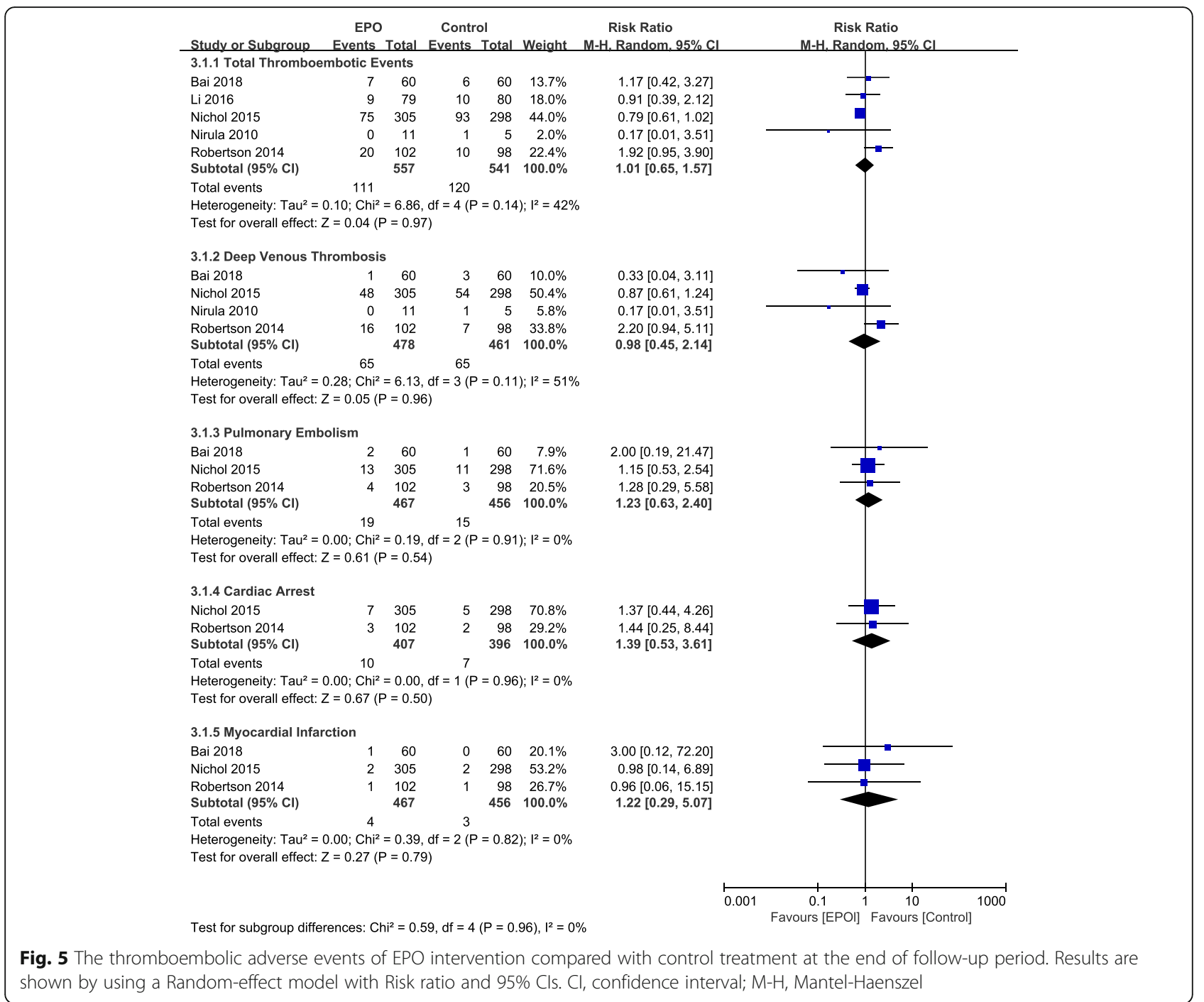

treatment withdrawal due to a perceived poor prognosis, whereas long-term mortality is believed to be mainly due to infection and multi-organ failure [15]. Our results may suggest the TBI patients may benefit from EPO treatment for its long-term effect, which may relate to its organ-protective effects [28].

\section{Neurological recovery}

Preclinical laboratory studies suggested that EPO may decrease local tissue hypoxia in the brain, improve function of the blood-brain barrier, decrease cerebral edema, and attenuate secondary brain injury, making EPO theoretically well suited to treat TBI [29]. However, our metaanalysis demonstrated no significant neurologic improvement in TBI patients following EPO treatment. This is concordant with Liu et al's conclusion [15]. Furthermore, our study demonstrated that there is no difference at each subgroup level of GOS and GOS-E systems.

The value of laboratory experiments for predicting the effectiveness of treatment strategies in clinical trials remains controversial. Several factors may contribute to the unguaranteed benefits in human trials compared with EPO being used in animal models. First, the characteristics of the experimental TBI tend to be simple and replicate only single factors in laboratory models [30]. None of these preclinical models adequately represents the complex situation of human TBI. The type and degree of injury can be standardized in preclinical models, in contrast, TBI in humans can result from a variety of etiologies such as the neglect of motorists, cyclists, construction workers and industrial workers in observing safety precautions, resulting in heterogeneous damage patterns including cranial fractures, intracerebral hemorrhage, cerebral 


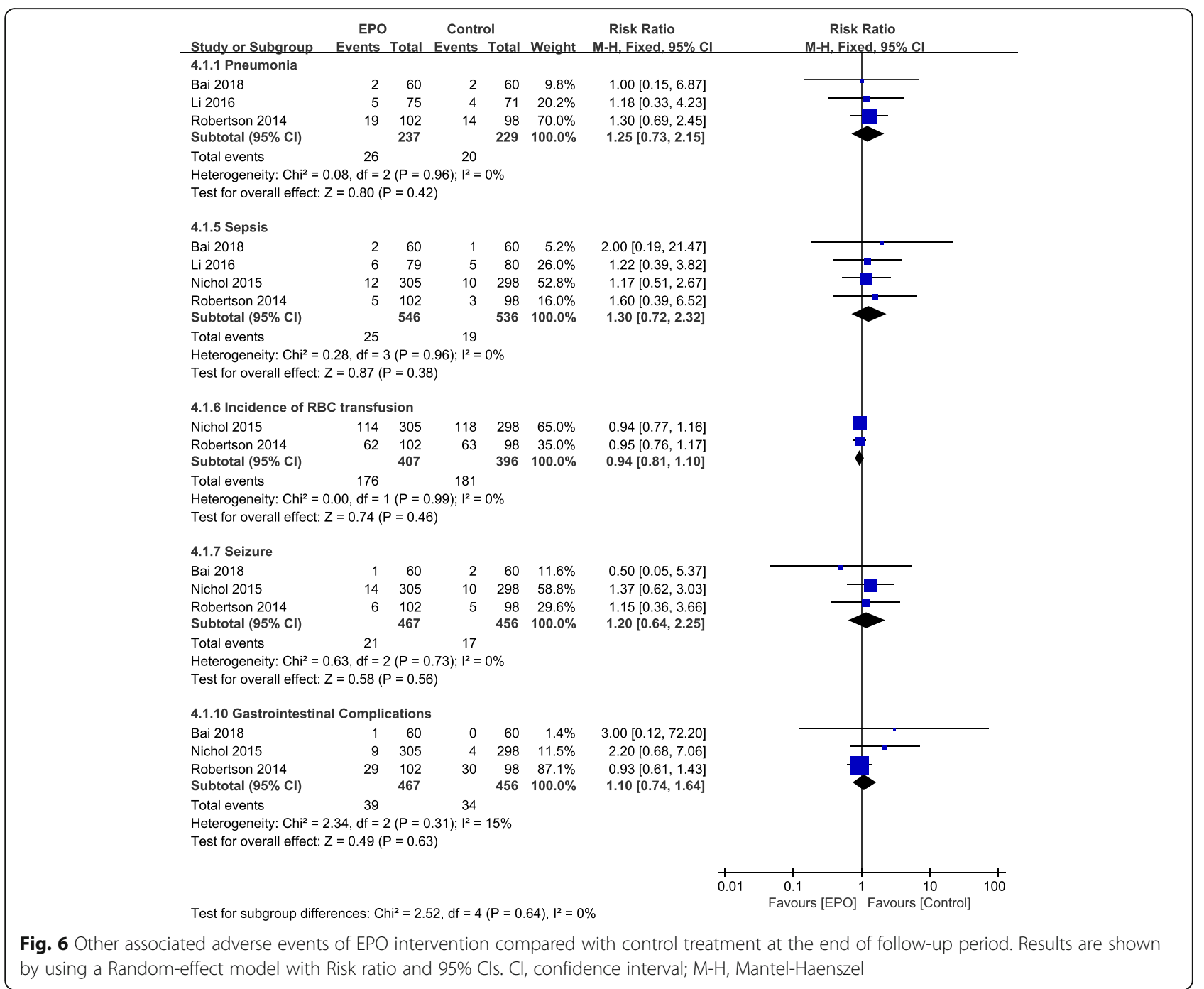

contusion, cerebral edema, and soft-tissue injuries [31]. Second, there are differences pathophysiological responses to neurotrauma between rodent and human, which may lead to different rates of survival as well as differences in neurological recovery [32]. A broad spectrum of secondary events, complex cascade of molecular and cellular events is triggered by the initial injury. This all contribute to cell death and/or degeneration and worsen patient neurological outcomes but could, at least theoretically, be counteracted $^{52}$. To preserve and restore the integrity, function, and connectivity of the brain cells and improve the patient's outcome, neuroprotective drugs should be administered as soon as possible and as long as the pathological cascades occur [33]. An experimental study in mice suggested the importance of the therapeutic time-window within $6 \mathrm{~h}$ after the initial TBI [34]. In laboratory studies, EPO can be administered as early as 5 min after injury [35], while this short time to intervention is not always possible in the clinical setting. However, the dose and timing of EPO injections varied greatly across RCTs in our study, and the current evidence is not strong enough to draw the conclusion that early intervention delivers better prognosis [36].

For optimal translation to the clinical situation for EPO treatment in TBI, preclinical studies should preferably be performed in more than one model and species to investigate the effects on both mechanistic and behavioral end points. Also, when initiating clinical studies, protocols should incorporate into early recognition and diagnosis of TBI, and timely intervention with EPO.

\section{Complication}

The EPO dose and therapeutic duration were not to reach a consensus, maybe due to the safety concerns of EPO has not been well established. Most of the evidence regarding the safety of EPO comes from its nonneurologic use; previous studies reported increased thromboembolic complications and/or mortality risks 


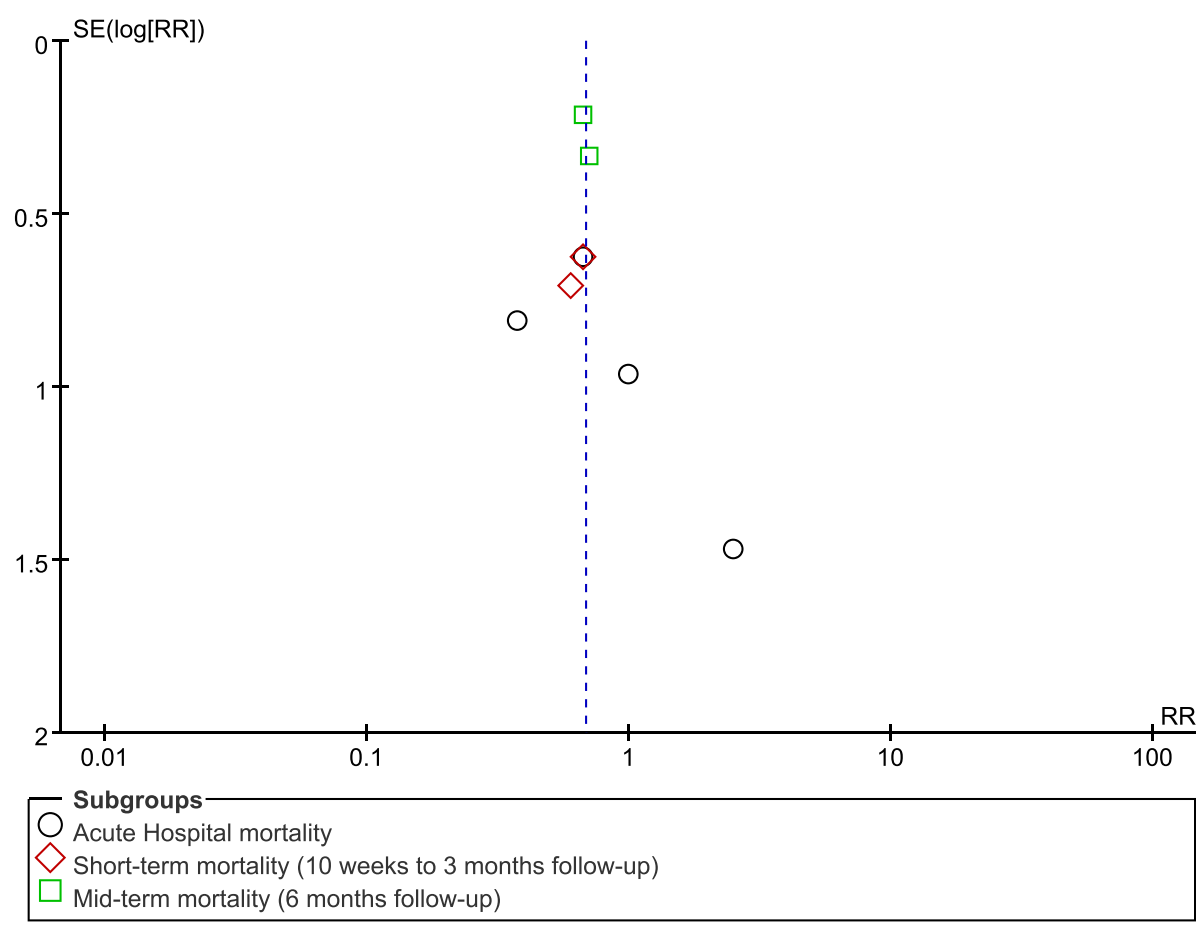

Fig. 7 Funnel plot for the detection of publication bias. The funnel plot of pooled studies that evaluated the effects of EPO on mortality appears to be symmetrical

with EPO administration to cancer patients, critically-ill patients and patients with kidney disease [37]. One prior study administered EPO to acute ischemic stroke patients, which showed that EPO therapy significantly improved long-term neurological outcomes in patients after ischemic stroke, but the long-term recurrent stroke and mortality rate did not differ between the EPOtreated and placebo-control group.

Our findings suggested that the use of EPO can be safe and well tolerated in TBI patients and does not increase the risk of complications. However, the interactions between EPO and various physiologic variables as well as drugs commonly used in TBI patients are unknown. Future studies should further investigate the safety profile of EPO for TBI, especially when other commonly-used drugs involving in.

\section{Limitations and weakness}

There are a number of limitations often inherent to meta-analyses that we encountered. First, the EPO treatment regimes differed across studies. The heterogeneity of the original RCTs may have reduced our ability to discern the true differences between the intervention and control arms. Second, the inclusion criteria for TBI patients across RCTs are vague and insufficient. TBI is a highly heterogeneous injury with a broad spectrum of symptoms, different level of initial TBI injury related to different therapeutic efficacy and outcomes [38, 39].
Third, the six-month mid-term follow-up time point is still a relatively brief time-window. Our analysis was limited by the varying follow-up durations of the included RCTs; further studies should conduct longer-term follow-up to continue coursing the efficacy and safety of EPO treatment for TBI. Forth, the neurological recovery should not be represented only by GOS and GOS-E, it will be more comprehensive and persuasive if the evaluation items include motor and sensory functions to assess gross and specific neurological function to TBI patients. Finally, there are limited published data evaluating EPO treatment for TBI, publication bias was strongly suspected even though not detected.

\section{Future aim}

Further exploration of molecular biomarkers should be anticipated to indicate the appropriate patients for EPO therapy after TBI [40]. Foundation of new appraisal system to assess the clinical effect is in demand, as with the originators of the GOS and GOS-E, survival is "an imperfect yardstick" in TBI. The current study did not demonstrate differences in neurologic recovery using the GOS and GOSE, but these scales are quite coarse and future studies should further investigate EPO as a neuroprotective intervention in TBI using more sensitive indicator suggested to detect the realistic slight, but still clinically meaningful, functional improvement. The time- and dose-response relationships of EPO treatment in TBI patients also needs 
to be better delineated. These aims can be accomplished with better homogenization of included patients, investigation of multiple dosages, standardization of intervention time, coupled with integrated multidimensional outcomes.

\section{Conclusions}

This meta-analysis highlights the potential mid-term survival benefit of EPO treatment for TBI without increasing the risk of adverse events. However, further well-designed investigations of the effect of EPO in TBI patients are warranted to guide management.

\section{Abbreviations}

Cl: Confidence interval; DVT: Deep vein thrombosis; EPO: Erythropoietin; GOS: Glasgow outcome scale; MD: Mean difference; RCT: Randomized controlled trial; RD: Risk difference; RR: Risk ratio; TBI: Traumatic brain injury

\section{Authors' contributions}

$\mathrm{KH}, \mathrm{HH}, \mathrm{BS}$ and ZW designed and conceptualized the study. ML, AJW and YC collected the data, $\mathrm{KH}, \mathrm{ML}, \mathrm{AJW}$ and $\mathrm{YC}$ analyzed and interpreted the data. $\mathrm{KH}, \mathrm{ML}$ and $\mathrm{YC}$ wrote the manuscript. $\mathrm{KH}, \mathrm{ML}, \mathrm{AJW}, \mathrm{GZ}, \mathrm{ZJ}, \mathrm{XW}, \mathrm{TZ}, \mathrm{DS}, \mathrm{BS}$ and ZW provided critical revisions that were important for the intellectual content. All authors read and approved the final version of the manuscript.

\section{Funding}

This work was supported by Shanghai Pujiang Program (KH, 19PJ1407500), Medical and Engineering Cross Research Fund from Shanghai Jiao Tong University (KH, YG2019QNA31), Shanghai Municipal Health Commission Clinical Study Special Fund (KH, 20194Y0067), Ruijin Hospital Guangci Excellence Youth Training Program (K.H, GCQN-2019-B10); Ruijin Youth NSFC Cultivation Fund (K.H, 2019QNPY01031).

\section{Availability of data and materials}

All data generated or analyzed during this study are included in this published article and its supplementary information files.

\section{Ethics approval and consent to participate}

Not applicable.

\section{Consent for publication}

Not applicable.

\section{Competing interests}

The authors declare that they have no competing interests.

\section{Author details}

${ }^{1}$ Department of Neurosurgery, Ruijin Hospital, Shanghai Jiao Tong University School of Medicine, No.197 Second Ruijin Street, Shanghai 200025, China. ${ }^{2}$ Center for Functional Neurosurgery, Ruijin Hospital, Shanghai Jiao Tong University School of Medicine, Shanghai 200025, China. ${ }^{3}$ Department of Biomedical Engineering, Columbia University, New York, NY 10027, USA ${ }^{4}$ Department of Neurosurgery, Massachusetts General Hospital, Harvard Medical School, Boston, MA 02114, USA. ${ }^{5}$ Department of Orthopedic Surgery, The First Affiliated Hospital of Chongqing Medical University, Chongqing 400016, China. ${ }^{6}$ State Key Laboratory of Oncology in South China, Sun Yat-sen University Cancer Center, Guangzhou 510060, China. ${ }^{7}$ Department of Neurosurgery, Ji Zhong Energy Fengfeng Group General hospital, Handan City 056200, China. ${ }^{8}$ Department of Neurosurgery, The PLA Navy Anqing Hospital, Anqing City 246000, China. ${ }^{9}$ Department of Neurosurgery, No.904th Hospital of The People's Liberation Army Joint Logistics Support Force, Wuxi 214000, China. ${ }^{10}$ Department of Traditional Chinese Medicine, Jing-an District Central Hospital, Shanghai 200437, China. ${ }^{11}$ Department of Neurosurgery, Third Affiliated Hospital, Second Military Medical University, Shanghai 200438, China. ${ }^{12}$ MGH-HMS Center for Nervous System Repair, Harvard Medical School, Boston, MA 02114, USA.
Received: 11 November 2019 Accepted: 14 October 2020

Published online: 02 November 2020

\section{References}

1. Hyder AA, Wunderlich CA, Puvanachandra P, Gururaj G, Kobusingye OC. The impact of traumatic brain injuries: a global perspective. NeuroRehabilitation. 2007:22(5):341-53.

2. CfDCa P. Nonfatal traumatic brain injuries related to sports and recreation activities among persons aged $</=19$ years--United States, 2001-2009. MMWR Morb Mortal Wkly Rep. 2011;60(39):1337-42.

3. Humphreys I, Wood RL, Phillips CJ, Macey S. The costs of traumatic brain injury: a literature review. Clin Econ Outcomes Res. 2013;5:281-7. https://doi. org/10.2147/ceor.s44625.

4. Werner C, Engelhard K. Pathophysiology of traumatic brain injury. Br J Anaesth. 2007:99(1):4-9. https://doi.org/10.1093/bja/aem131.

5. Jullienne A, Obenaus A, Ichkova A, Savona-Baron C, Pearce WJ, Badaut J. Chronic cerebrovascular dysfunction after traumatic brain injury. J Neurosci Res. 2016;94(7):609-22. https://doi.org/10.1002/jnr.23732.

6. Kinoshita K. Traumatic brain injury: pathophysiology for neurocritical care. J Intensive Care. 2016:4:29. https://doi.org/10.1186/s40560-016-0138-3.

7. Janowitz T, Menon DK. Exploring new routes for neuroprotective drug development in traumatic brain injury. Sci Transl Med. 2010;2(27):27rv1. https://doi.org/10.1126/scitranslmed.3000330.

8. Jelkmann W. Physiology and pharmacology of erythropoietin. Transfus Med Hemother. 2013;40(5):302-9. https://doi.org/10.1159/000356193.

9. Noxon V, Knopf KB, Norris LB, Chen B, Yang YT, Qureshi ZP, et al. Tale of two erythropoiesis-stimulating agents: utilization, dosing, litigation, and costs of Darbepoetin and Epoetin among South Carolina Medicaid-covered patients with Cancer and chemotherapy-induced Anemia. J Oncol Pract. 2017:13(6):e562-e73. https://doi.org/10.1200/JOP.2016.019364.

10. Bramlett HM, Dietrich WD, Dixon CE, Shear DA, Schmid KE, Mondello S, et al. Erythropoietin treatment in traumatic brain injury: operation brain trauma therapy. J Neurotrauma. 2016;33(6):538-52. https://doi.org/10.1089/ neu.2015.4116.

11. Cherian L, Goodman JC, Robertson C. Neuroprotection with erythropoietin administration following controlled cortical impact injury in rats. J Pharmacol Exp Ther. 2007;322(2):789-94. https://doi.org/10.1124/jpet.107. 119628.

12. Peng $W$, Xing Z, Yang J, Wang $Y$, Wang W, Huang W. The efficacy of erythropoietin in treating experimental traumatic brain injury: a systematic review of controlled trials in animal models. J Neurosurg. 2014;121(3):65364. https://doi.org/10.3171/2014.6.jns132577.

13. Kabadi SV, Faden Al. Neuroprotective strategies for traumatic brain injury: improving clinical translation. Int J Mol Sci. 2014;15(1):1216-36. https://doi. org/10.3390/ijms15011216.

14. Grasso G, Alafaci C, Buemi M. Erythropoietin in traumatic brain injury: an answer will come soon. World Neurosurg. 2015;84(5):1491-2. https://doi.org/ 10.1016/j.wneu.2015.05.056

15. Liu WC, Wen L, Xie T, Wang H, Gong JB, Yang XF. Therapeutic effect of erythropoietin in patients with traumatic brain injury: a meta-analysis of randomized controlled trials. J Neurosurg. 2016:1-8. https://doi.org/10.3171/ 2016.4.jns152909.

16. Moher D, Shamseer L, Clarke M, Ghersi D, Liberati A, Petticrew M, et al. Preferred reporting items for systematic review and meta-analysis protocols (PRISMA-P) 2015 statement. Syst Rev. 2015:4:1. https://doi.org/10.1186/2046-4053-4-1.

17. Higgins JP, Altman DG, Gotzsche PC, Juni P, Moher D, Oxman AD, et al. The cochrane collaboration's tool for assessing risk of bias in randomised trials. BMJ. 2011;343:d5928. https://doi.org/10.1136/bmj.d5928.

18. Higgins JP, Thompson SG, Deeks JJ, Altman DG. Measuring inconsistency in meta-analyses. BMJ. 2003;327(7414):557-60. https://doi.org/10.1136/bmj.327. 7414.557.

19. Macaskill P, Walter SD, Irwig L. A comparison of methods to detect publication bias in meta-analysis. Stat Med. 2001;20(4):641-54. https://doi. org/10.1002/sim.698

20. Li ZM, Xiao YL, Zhu JX, Geng FY, Guo CJ, Chong ZL, et al. Recombinant human erythropoietin improves functional recovery in patients with severe traumatic brain injury: a randomized, double blind and controlled clinical trial. Clin Neurol Neurosurg. 2016;150:80-3. https://doi.org/10.1016/j.clineuro. 2016.09.001

21. Nichol A, French C, Little L, Haddad S, Presneill J, Arabi Y, et al. Erythropoietin in traumatic brain injury (EPO-TBI): a double-blind 
randomised controlled trial. Lancet. 2015;386(10012):2499-506. https://doi. org/10.1016/s0140-6736(15)00386-4.

22. Bai $X-F$, Gao $Y-K$. Recombinant human erythropoietin for treating severe traumatic brain injury. Medicine. 2018:97:1. https://doi.org/10.1097/md. 0000000000009532.

23. Aloizos S, Evodia E, Gourgiotis S, Isaia EC, Seretis C, Baltopoulos G]. Neuroprotective effects of erythropoietin in patients with severe closed brain injury. Turk Neurosurg. 2015;25(4):552-8. https://doi.org/10.5137/10195149.JTN.9685-14.4

24. Abrishamkar S, Safavi M, Honarmand A. Effect of erythropoietin on Glasgow coma scale and Glasgow outcome Sale in patient with diffuse axonal injury. J Res Med Sci. 2012;17(1):51-6.

25. Nirula R, Diaz-Arrastia R, Brasel K, Weigelt JA, Waxman K. Safety and efficacy of erythropoietin in traumatic brain injury patients: a pilot randomized trial. Crit Care Res Pract. 2010;2010. https://doi.org/10.1155/2010/209848.

26. Robertson CS, Hannay HJ, Yamal JM, Gopinath S, Goodman JC, Tilley BC, et al. Effect of erythropoietin and transfusion threshold on neurological recovery after traumatic brain injury: a randomized clinical trial. JAMA. 2014; 312(1):36-47. https://doi.org/10.1001/jama.2014.6490.

27. Roozenbeek B, Maas Al, Marmarou A, Butcher I, Lingsma HF, Lu J, et al. The influence of enrollment criteria on recruitment and outcome distribution in traumatic brain injury studies: results from the impact study. J Neurotrauma. 2009;26(7):1069-75. https://doi.org/10.1089/neu.2008.0569.

28. Loane DJ, Faden Al. Neuroprotection for traumatic brain injury: translational challenges and emerging therapeutic strategies. Trends Pharmacol Sci. 2010;31(12):596-604. https://doi.org/10.1016/j.tips.2010.09.005.

29. Chu H, Ding $H$, Tang $Y$, Dong Q. Erythropoietin protects against hemorrhagic blood-brain barrier disruption through the effects of aquaporin-4. Lab Invest. 2014;94(9):1042-53. https://doi.org/10.1038/ labinvest.2014.84.

30. Cernak I. Animal models of head trauma. NeuroRx. 2005;2(3):410-22. https:// doi.org/10.1602/neurorx.2.3.410

31. Saatian M, Ahmadpoor J, Mohammadi Y, Mazloumi E. Epidemiology and pattern of traumatic brain injury in a developing country regional trauma center. Bull Emerg Trauma. 2018;6(1):45-53. https://doi.org/10.29252/beat-060107.

32. de Vries RB, Wever KE, Avey MT, Stephens ML, Sena ES, Leenaars M. The usefulness of systematic reviews of animal experiments for the design of preclinical and clinical studies. ILAR J. 2014;55(3):427-37. https://doi.org/10 1093/ilar/ilu043.

33. Pearn ML, Niesman IR, Egawa J, Sawada A, Almenar-Queralt A, Shah SB, et al. Pathophysiology associated with traumatic brain injury: current treatments and potential novel therapeutics. Cell Mol Neurobiol. 2017;37(4): 571-85. https://doi.org/10.1007/s10571-016-0400-1.

34. Brines ML, Ghezzi P, Keenan S, Agnello D, de Lanerolle NC, Cerami C, et al. Erythropoietin crosses the blood-brain barrier to protect against experimental brain injury. Proc Natl Acad Sci U S A. 2000;97(19):10526-31. https://doi.org/10.1073/pnas.97.19.10526.

35. Grasso G, Sfacteria A, Meli F, Fodale V, Buemi M, lacopino DG. Neuroprotection by erythropoietin administration after experimental traumatic brain injury. Brain Res. 2007;1182:99-105. https://doi.org/10.1016/j. brainres.2007.08.078.

36. Zoerle T, Carbonara M, Zanier ER, Ortolano F, Bertani G, Magnoni S, et al. Rethinking Neuroprotection in severe traumatic brain injury: toward bedside Neuroprotection. Front Neurol. 2017;8:354. https://doi.org/10.3389/fneur. 2017.00354.

37. Corwin HL, Gettinger A, Fabian TC, May A, Pearl RG, Heard S, et al. Efficacy and safety of epoetin alfa in critically ill patients. N Engl J Med. 2007;357(10): 965-76. https://doi.org/10.1056/NEJMoa071533.

38. Lingsma HF, Roozenbeek B, Steyerberg EW, Murray GD, Maas AIR. Early prognosis in traumatic brain injury: from prophecies to predictions. Lancet Neurol. 2010;9(5):543-54. https://doi.org/10.1016/S1474-4422(10)70065-X.

39. Perel P, Arango M, Clayton T, Edwards P, Komolafe E, Poccock S, et al. Predicting outcome after traumatic brain injury: practical prognostic models based on large cohort of international patients. BMJ. 2008;336(7641):425-9. https://doi.org/10.1136/bmj.39461.643438.25.

40. Skolnick BE, Maas Al, Narayan RK, van der Hoop RG, MacAllister T, Ward JD, et al. A clinical trial of progesterone for severe traumatic brain injury. N Engl J Med. 2014;371(26):2467-76. https://doi.org/10.1056/ NEJMoa1411090.

\section{Publisher's Note}

Springer Nature remains neutral with regard to jurisdictional claims in published maps and institutional affiliations.

\section{Ready to submit your research? Choose BMC and benefit from:}

- fast, convenient online submission

- thorough peer review by experienced researchers in your field

- rapid publication on acceptance

- support for research data, including large and complex data types

- gold Open Access which fosters wider collaboration and increased citations

- maximum visibility for your research: over $100 \mathrm{M}$ website views per year

At BMC, research is always in progress.

Learn more biomedcentral.com/submissions 